\title{
Stiffness Characteristics of High-Speed Railway Turnout and the Effect on the Dynamic Train-Turnout Interaction
}

\author{
Jingmang Xu, ${ }^{1,2}$ Ping Wang, ${ }^{1,2}$ Xiaochuan Ma, ${ }^{1,2}$ Yuan Gao, ${ }^{1,2}$ and Rong Chen ${ }^{1,2}$ \\ ${ }^{1}$ MOE Key Laboratory of High-Speed Railway Engineering, Southwest Jiaotong University, Chengdu 610031, China \\ ${ }^{2}$ School of Civil Engineering, Southwest Jiaotong University, Chengdu, Sichuan 610031, China \\ Correspondence should be addressed to Rong Chen; chenrong@home.swjtu.edu.cn
}

Received 1 October 2016; Revised 15 November 2016; Accepted 27 November 2016

Academic Editor: Georges Kouroussis

Copyright (c) 2016 Jingmang Xu et al. This is an open access article distributed under the Creative Commons Attribution License, which permits unrestricted use, distribution, and reproduction in any medium, provided the original work is properly cited.

\begin{abstract}
Track stiffness in railway turnouts is variable due to differences in structural composition along the longitudinal direction, which will lead to severe dynamic interaction between train and turnout. In this paper, a transient analysis model is presented to investigate the stiffness characteristics of high-speed railway turnouts based on the finite element method and is applied to optimise the stiffness of railway turnouts. Furthermore, the effect of the stiffness variations on the dynamic train-turnout interaction is analysed. The calculation results show that the track stiffness characteristics are similar in the main and diverging line of railway turnout, except for the check rail sections. Due to the existence of shared baseplates and spacer blocks between different rails, the stiffness variations in the crossing panel are most severe in high-speed railway turnouts. The stiffness differences (calculated as the ratio of the maximum and minimum stiffness) of the longitudinal and lateral direction for Chinese number 18 ballasted turnout are 216\% and 229\%, respectively. The graded stiffness of the tie pads has been redesigned to optimise the stiffness of railway turnout based on the transient analysis model and the stiffness differences of the turnout are decreased. Altogether, the dynamic train-turnout interaction is enhanced remarkably by considering the turnout's stiffness characteristics.
\end{abstract}

\section{Introduction}

Railway turnouts are essential components of railway infrastructure, providing flexibility in traffic operations. Highspeed turnouts, specifically, are comprised of a switch panel, a movable point crossing panel, and a closure panel for high-speed railway. To enable a vehicle to change between tracks, the switch and point rail profiles are designed to vary in switch and crossing panels. The variation of rail profiles changes the boundary conditions of wheel-rail contact, and the combination of switch rail and stock rail to bear wheel loads together makes multipoint contact more common in railway turnouts. Normal wheel-rail contact situations are disturbed when a wheel transfers from stock rail to switch rail in the switch panel or from wing rail to point rail in the crossing panel [1]. Furthermore, to ensure the structural integrity and stability of railway turnouts, such turnout rails are connected by the shared iron plate of different lengths or the spacer block. This leads to variations in the stiffness of railway turnouts.
Dynamic interactions between train and track are influenced significantly by track stiffness variations and can be improved by adjustments in the track stiffness [2]. Varandas et al. presented a numerical model for the dynamic loads on the ballast caused by trains passing a transition; the nonconstant stiffness of the support affected the dynamic behaviour of railway track on transitions zones significantly [3]. Woodward et al. applied a polyurethane reinforcement of the ballast to modify railway track stiffness, and the effect on the track stiffness was examined by full-scale testing of railway track under laboratory conditions [4]. Nielsen et al. presented a hybrid model for the prediction of groundborne vibration due to discrete wheel and rail irregularities, and spatial variation of support stiffness was accounted for [5]. Kouroussis et al. presented a vehicle/track/soil numerical railway model to analyse the ground vibrations generated by local irregularities, and the effect of track flexibility variation was investigated $[6,7]$.

Due to the transfer of wheels and the variations in track stiffness, dynamic train-turnout interaction is a time-variant 
process, even when discounting track irregularities. Moreover, it is far more complex than that of ordinary track. Such conditions will ultimately lead to the transmission of noise and vibrations into the outside environment, thus significantly affecting the operating behaviour of railway vehicles in terms of motion stability, riding comfort, and derailment prevention $[8,9]$. Dynamic train-turnout interaction caused by complicated contact conditions of railway turnouts has been mainly studied. Sebes et al. applied the semi-Hertzian method to solve the wheel-rail contact problem in simulating the dynamic interaction between a vehicle and high-speed switch. This approach enables the derivation of contact patches that are more arbitrarily shaped [10]. Kassa et al. developed two multibody system models for simulating the dynamic train-turnout interaction, accounting for both the variation in rail profile and the contact between wheel flange and the check rail, but the track model of railway turnout was assumed to be rigid [11]. Furthermore, the simulation of dynamic train-turnout interaction and finite element analysis were combined to simulate profile evolution due to plastic deformation [12]. Bruni et al. proposed and compared two different models for simulating the dynamic interaction between train and turnout, and the particular geometry of wheel-rail contact and the track flexibility variations were considered in the simulation [13]. Alfi and Bruni proposed a mathematical model of train-turnout interaction in the mid-frequency range and presented comprehensive results of train-turnout interaction during the negotiation of the main and diverging lines, including the effect of different wheel/rail profiles and presence of track misalignment [14]. Zhu and Thompson presented a calculation model based on the finite element method to study the effect of articulated switch sleepers on the dynamic train-turnout interaction. The nonlinear characteristics of the ballast's support stiffness are considered [15]. Sun et al. developed a method using commercial software VAMPIRE to determine the wheel impact forces generated by the variation of wheel-rail contact, and the effect of turnout curve and crossing on the wheel impact forces was investigated [9].

The dynamic simulations have helped to research the damage mechanisms and guide the structure optimisation of railway turnouts. Pålsson and Nielsen applied a genetic-type algorithm to solve the problem of track gauge optimisation in the switch panel. The dynamic train-turnout interaction was simulated by using the commercial software GENSYS and the vertical track properties are modelled with input data based on the measured track stiffness [16]. Li et al. applied the multibody vehicle dynamics in the simulation of dynamic vehicle-turnout interaction considering spacedependent track properties, and the simulated dynamic responses were used as inputs for simulating track settlement in railway turnouts [17]. Wan et al. developed a twodimensional finite element model to analyse the vertical dynamic train-turnout interactions. Passenger trains negotiating turnouts with varying crossing angles, rail geometry, and service condition are considered in the simulation [18]. $\mathrm{Xu}$ et al. applied the multibody system SIMPACK and finite element software ANSYS to calculate the features of load and subsequent distributions of contact stresses and internal stresses on different regions of wheel-turnout components [19] and presented a numerical simulation tool to simulate the rail profile evolution in the switch panel of a railway turnout, but the track models were taken as rigid in the dynamic interaction [20].

The variations in track stiffness for railway turnouts have a significant effect on the dynamic train-turnout interaction [21]. Although the rail damage and dynamic interaction could be improved by tuning elastic track properties [22] or using more resilient rail pads [23], there are few studies on the distribution of stiffness or optimisation of railway turnouts, especially in terms of improving motion stability and riding comfort when a train is passing at high speed. In this paper, a transient analysis model is proposed to study the distribution of stiffness in high-speed railway turnouts based on finite element method; meanwhile, the pads' stiffness under shared base plates is redesigned and optimised in different sections to improve the variations in stiffness, and it is evaluated by simulations of dynamic train-turnout interaction. The results of this study could provide some guidance for the turnout design and optimisation of railway turnouts that minimise vibration and noise transmission and improves riding comfort in high-speed turnout systems.

\section{Numerical Analysis of Stiffness Distribution}

2.1. Numerical Analysis Model. As railway turnouts have different types of rails, as well as different lengths of sleepers and base plates, with additional components as spacer blocks, displacement restrictors, slide base plates, and shared base plates coupled to the turnout rails, the stiffness of the turnout rails varies along the longitudinal direction of the railway line. In particular, turnout rails include stock rails, switch rails, wing rails, point rails, and check rails. The crosssections and bending stiffness differ and both switch rails and point rails have variable cross-sections. Long turnout sleepers must support the four rails of the main and diverging lines simultaneously. Acting on a main line, train loads can also be transferred to the rails of another line through turnout sleepers, allowing them to bear part of the train load. Two or more rails share the base plate at the switch panel, the end of closure panel, and crossing panel. Since more than one rail shares one base plate, the wheel load can be transferred from one line to the rail of another effectively. Moreover, to allow more than one rail to share one base plate, the length of the shared base plate and the stiffness of the pads underneath them vary, causing changes in the track stiffness along the longitudinal direction. The switch rails and the movable point rails can be pulled freely from the slide base plate. In other words, switch rails, point rails, and slide base plates are not restricted by fasteners. To ensure the longitudinal force transmission of the welded turnout and the geometric stability of the rails, spacer blocks are set up at the end of the switch panel, between the two closure rails at the front of the point rail, between the long and short point rails and between the wing rail and the point rail. This allows two rails to bear the wheel load together and increases the integral stiffness at the corresponding position of the track. 
Considering the characteristics of the high-speed railway turnout structure as described in Figure 1, a numerical analysis model for track stiffness of the turnout zone can be established based on the finite element method. The stock rail, closure panel rail, wing rail, check rail, spacer block, and base plate are simulated in the analysis model with uniform crosssection beam elements. The switch rails and movable point rails are simulated with variable cross-section beam elements, and the coupling between them and the slide bedplate are both simulated with nonlinear springs; the pads under the rails and base plates as well as the granular ballast bed are simulated with distributed linear springs [24]. The turnout sleepers are simulated with the finite beam elements of the elastic subgrade. For the analysis, a train load is simulated with a transient moving load. The above comprehensive finite element model of high-speed railway turnout is applied to calculate the rail displacement; the track stiffness of the turnout can be obtained on the basis of the relationship between the load and rail displacement [25]. It is worth pointing out that the stiffness of railway turnout is calculated by applying a moving load and the inertia and damping of the finite element model are neglected in the calculation.

For the stiffness analysis model, the deformation and force exerted on different types of rails, spacer blocks, and base plates are simulated with a Timoshenko beam. The Timoshenko beam is a 3D beam element and has two nodes (Figure 2), and each node has six degrees of freedom, namely, translational degrees of freedom and rotational degrees of freedom, along the axes of $x, y$, and $z$.

$\left[K_{e}\right]$

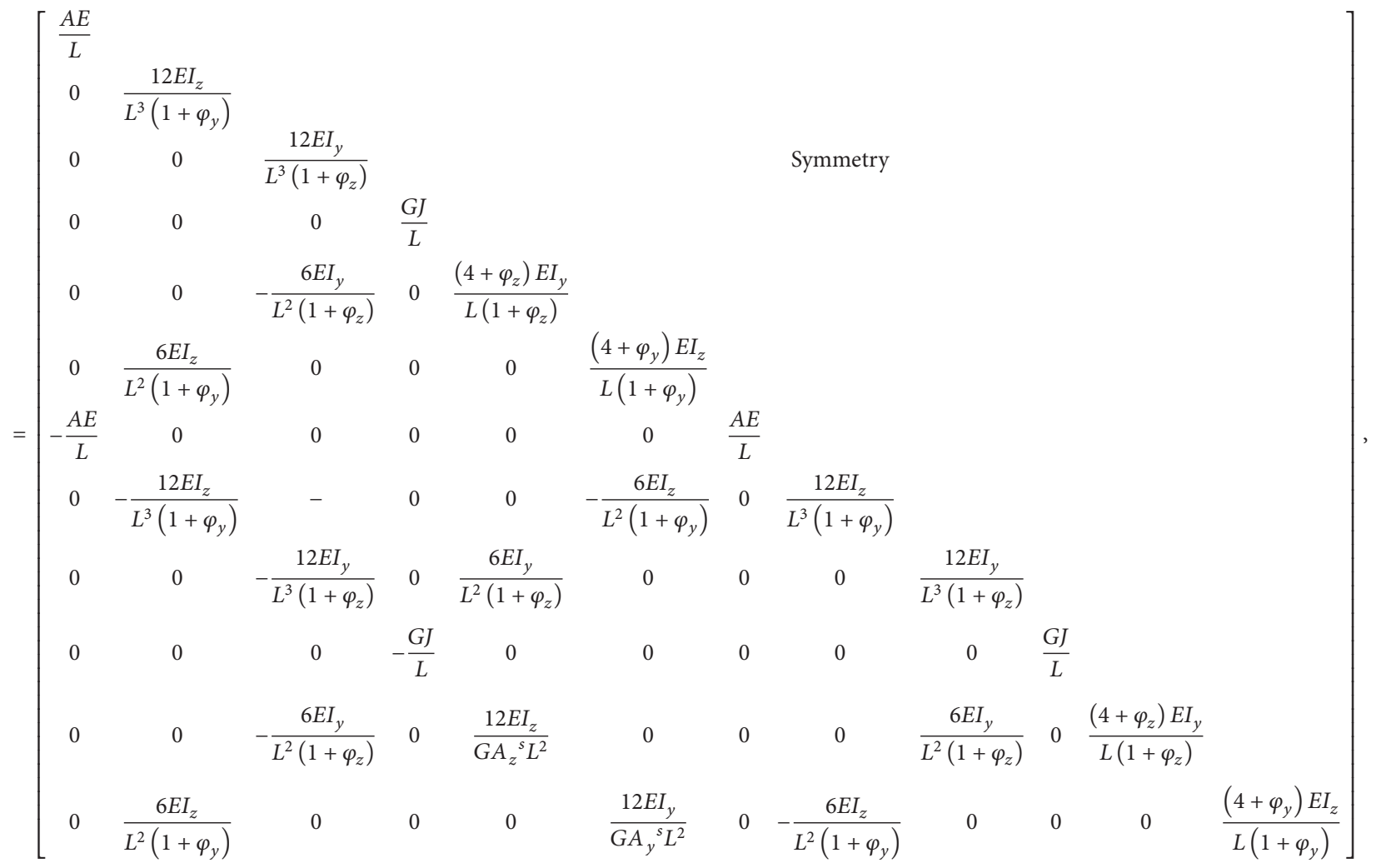

The displacements between two adjacent nodes for the 3D beam elements can be derived and obtained as the following equation, which can be used to calculate track stiffness at shorter intervals than the distance between nodes:

$$
\begin{aligned}
u & =\frac{1}{2}\left(u_{i}(1-s)+u_{j}(1+s)\right) \\
v & =\frac{1}{2}\left(v_{i}(1-s)+v_{j}(1+s)\right) \\
w & =\frac{1}{2}\left(w_{i}(1-s)+w_{j}(1+s)\right) \\
\theta_{x} & =\frac{1}{2}\left(\theta_{x i}(1-s)+\theta_{x j}(1+s)\right) \\
\theta_{y} & =\frac{1}{2}\left(\theta_{y_{i}}(1-s)+\theta_{y j}(1+s)\right) \\
\theta_{z} & =\frac{1}{2}\left(\theta_{z i}(1-s)+\theta_{z j}(1+s)\right),
\end{aligned}
$$

where $u, v$, and $w$ are the respective translational displacements along the axes of $x, y$, and $z, \theta_{x}, \theta_{y}$ and $\theta_{z}$ are rotational displacements along the axes of $x, y$, and $z$, and $s$ is the ratio of the local coordinates and half of element length.

The stiffness matrix of the 3D beam element derived according to the minimum potential energy principle is as follows: 


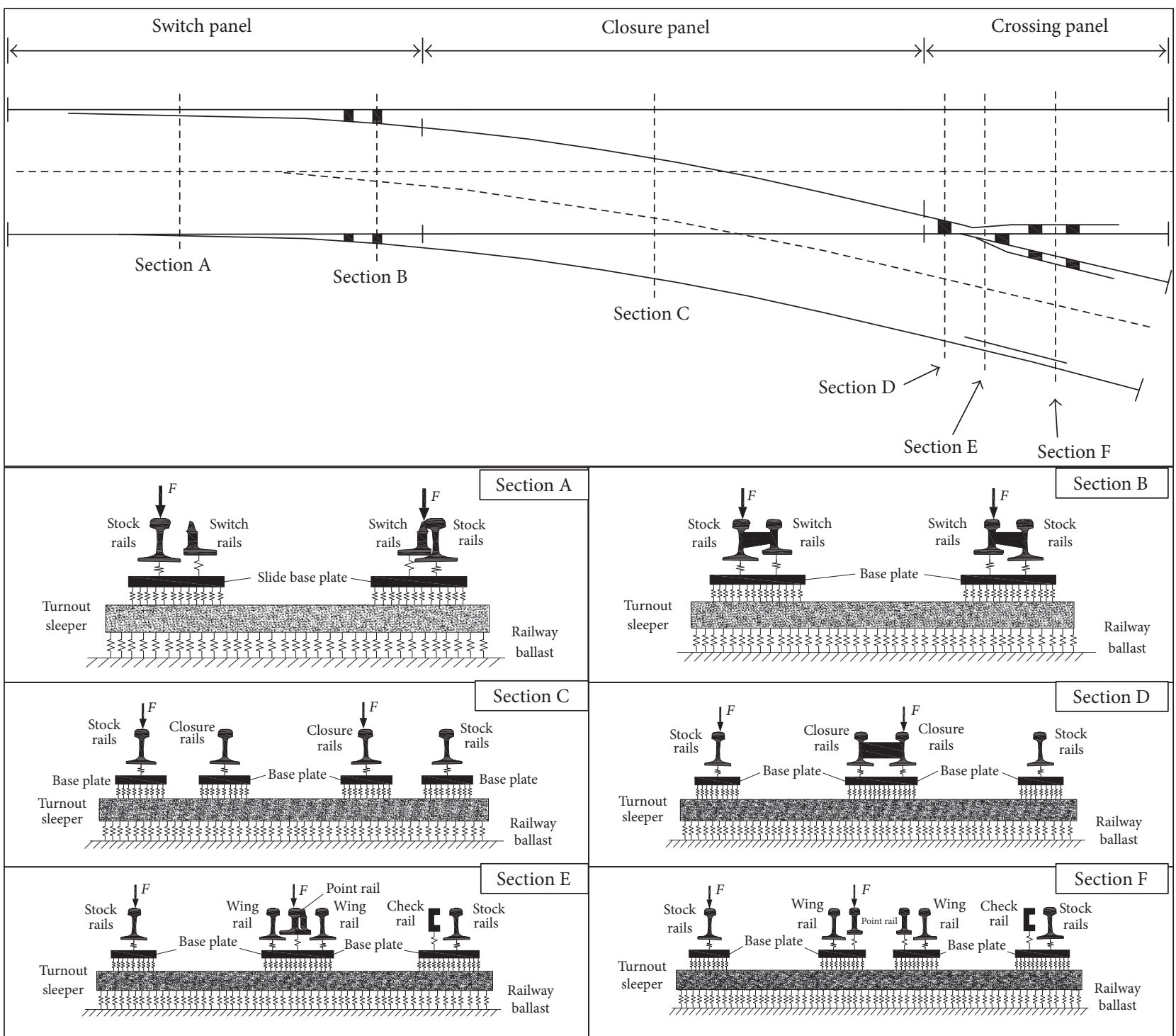

FIGURE 1: Characteristics of a high-speed turnout structure.

where $\varphi_{y}=24(1+u) A r_{y}^{2} / A_{z} l^{2}, \varphi_{z}=24(1+u) A r_{z}^{2} / A_{y} l^{2}$, and $r_{y}$ and $r_{z}$ refer to the $y$ - and $z$-axes gyration radius. $E$ and $G$ refer to the elastic modulus and the shear modulus, respectively. $L$ and $A$ refer to the length and cross-sectional area of the beam element. $I_{y}, I_{z}$, and $J$ refer to the $y$-axis, $z$ axes, and twisting inertia moments for the cross-section of the beam element, respectively. $A_{y}$ and $A_{z}$ refer to the shearing cross-section areas of the beam element perpendicular to the $y$ - and $z$-axes.

For the presented stiffness analysis model, the continuously supported beam element is used to simulate the turnout sleepers, and the spring element is used to simulate the elastic support of pads and granular ballast beds. Their element shape functions and stiffness matrices can be derived according to Formulas (1) and (2).

The node-element information and system equation can be established by using MATLAB software tool according to the finite element stiffness matrices and load vector equation in relation to the different parts of the turnout stiffness analysis model as follows:

$$
[K]\{u\}=\{f\}
$$

where $[K]$ refers to the system stiffness matrix of the analysis model, $\{u\}$ refers to the system displacement vector of the analysis model, and $\{f\}$ refers to the system load vector of the analysis model. The displacement of each node under the moving load is calculated based on the direct integral calculus method of NEWMARK, and then the track stiffness at a turnout rail node can be obtained by considering the relationship between the load and displacement. Furthermore, the maximum element size for rails in the stiffness analysis model is taken as $0.01 \mathrm{~m}$ to guarantee the accuracy of the calculation results. 
TABLE 1: Cross-section parameters of high-speed turnout rails.

\begin{tabular}{lcccc}
\hline Rail type & $\begin{array}{c}\text { Cross-section area } \\
\left(\mathrm{cm}^{2}\right)\end{array}$ & $\begin{array}{c}\text { Height } \\
(\mathrm{mm})\end{array}$ & $\begin{array}{c}\text { Vertical moment of inertia } \\
\left(\mathrm{cm}^{4}\right)\end{array}$ & $\begin{array}{c}\text { Lateral moment of inertia } \\
\left(\mathrm{cm}^{4}\right)\end{array}$ \\
\hline CN60 rail & 77.45 & 176 & 3217 & 524 \\
CN60AT rail & 104.2 & 152 & 2500 & 906 \\
Check rail & 65.8 & 152 & 2037 & 377 \\
\hline
\end{tabular}

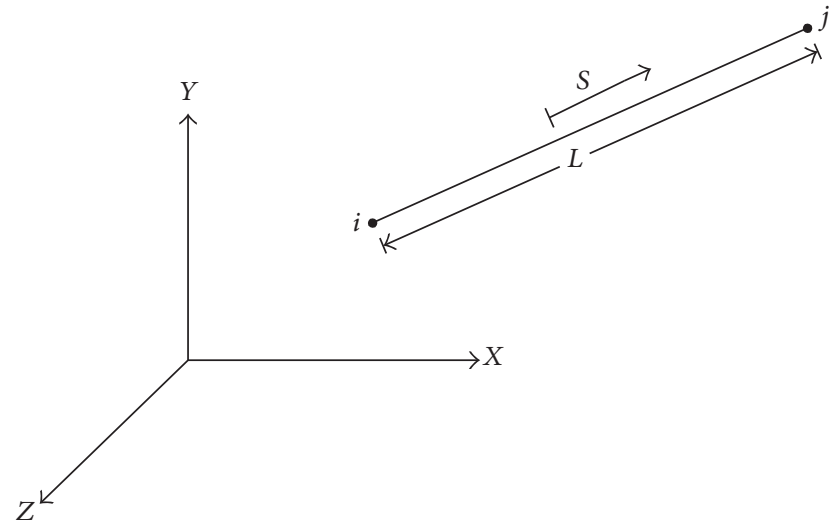

Figure 2: 3D beam elements.

\subsection{Distribution of Stiffness in Railway Turnouts}

2.2.1. Structure Parameters of High-Speed Turnouts. Taking the number 18 high-speed ballast turnout of a special passenger line in China as an example (Figure 3), the sleeper pitch is $0.6 \mathrm{~m}$. Different types of rails in the high-speed turnout zone are all made of the same material. The elastic modulus and Poisson's ratio are $2.06 \times 10^{11} \mathrm{~Pa}$ and 0.3 , respectively. The material parameters of the iron base plates, slide base plates, and spacer blocks are the same as those of the rails. In addition, the turnout sleepers are made of C60 concrete. The elastic modulus and Poisson's ratio are $3.65 \times 10^{10} \mathrm{~Pa}$ and 0.15 , respectively.

The stock rail and wing rail of the high-speed turnout are made with $\mathrm{CN} 60$ rails. Meanwhile, the switch rail and movable point rail are made with CN60AT rails, and the check rail is made with sliced channel rail. Their cross-section parameters are as shown in Table 1. The stiffness of the fastener system is mainly provided by the pads under the rails and iron base plates. The pads under the rails have the same supporting stiffness, namely, $200 \mathrm{kN} / \mathrm{mm}$. The stiffness of the pads under the iron base plates varies linearly with the length of the shared base plates. The supporting stiffness of pads under iron base plates is $100(\mathrm{kN} / \mathrm{mm}) / \mathrm{m}$. The supporting stiffness of the ballast bed under turnout sleepers is a constant support bed modulus of $107(\mathrm{kN} / \mathrm{mm}) / \mathrm{m}$.

2.2.2. Calculation Results. The distribution of track stiffness in the turnout zone is studied by using the above stiffness analysis model in order to establish a basis for optimising the track stiffness in turnout zones. The distribution of track stiffness in the main and diverging lines of the high-speed turnout is provided (Figure 4).
As shown in Figures 4(a) and 4(b), the track stiffness of the straight stock rail is around $97 \mathrm{kN} / \mathrm{mm}$ at the switch panel and $86 \mathrm{kN} / \mathrm{mm}$ at the closure panel and crossing panel. This is due to the stock rail and point rail sharing the single iron base plate at the switch panel. In addition, a pad with high supporting stiffness is used. Although distribution of the track stiffness along the curved stock rail is nearly the same as that of the straight stock rail at the switch and closure panels, however the curved rail shares the base plate of the check rail at the crossing panel, leading to an increase of the track stiffness of the curved stock rail (up to $101 \mathrm{kN} / \mathrm{mm}$ ). The track stiffness of the main inner rail is $92-101 \mathrm{kN} / \mathrm{mm}$ at the switch panel and is $93 \mathrm{kN} / \mathrm{mm}$ at the closure panel and the rear part of the turnout. Track stiffness in the crossing panel is high and varies significantly along the longitudinal direction. Track stiffness increases greatly from the iron base plate shared by the two rails at the end of the closure panel and reaches a peak value of $199 \mathrm{kN} / \mathrm{mm}$ at the center of the crossing panel. In the crossing panel, the track stiffness of the inner rails is over $110 \mathrm{kN} / \mathrm{mm}$ and has the following three peak values. The first peak appears $54 \mathrm{~m}$ away from the front of the turnout. Here, the two rails are connected with spacer blocks, and, due to the strong connection of between the two rails, a single iron base plate is shared (Figure 1, Section D). The second peak appears $63 \mathrm{~m}$ away from the front of the turnout. At this value, a single iron base plate is shared by the long/short point rails and two wing rails (Figure 1, Section E), which is caused by the restriction of the short point rail and two wing rails on the long point rail. The third peak appears $67 \mathrm{~m}$ away from the front of the turnout. This is located at the end of the crossing panel where the point rail and wing rail are connected with spacer blocks (Figure 1, Section F), which is caused by the restriction of the wing rail on the point rail. The distribution of track stiffness value in the diverging line is the same as that of the main line.

As shown in Figures 4(c) and 4(d), since the spacer blockers connect the rails and more than one rail shares the iron base plate at the crossing panel, the track stiffness of the inner rail at this section is higher than that of the stock rail, with a maximum differential of 2.29 times. The result of the difference between the track stiffness of the inner rail and the stock rail in the switch panel and closure panel is minor; the maximum difference is only $10 \%$. Moreover, the track stiffness of each turnout rail varies along the longitudinal direction. Taking the main line as an example, the maximum value in track stiffness of the stock rail is 1.13 times that of the minimum one. For the inner rail, the maximum value in track stiffness is 2.16 times that of the minimum one. This indicates that the structural arrangement of the high-speed turnout can cause obvious height and level irregularities under the 


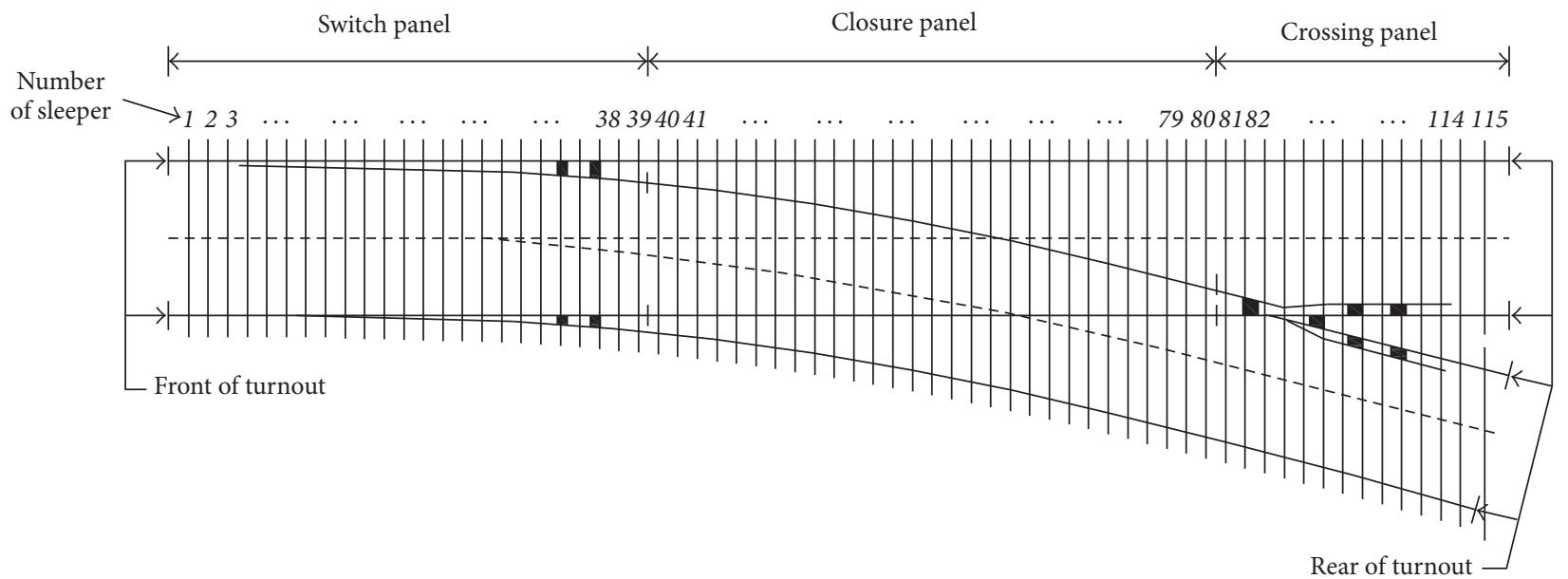

FIGURE 3: Sleeper arrangement of the \#18 high-speed turnout in China (the sleeper pitch is $0.6 \mathrm{~m}$ ).

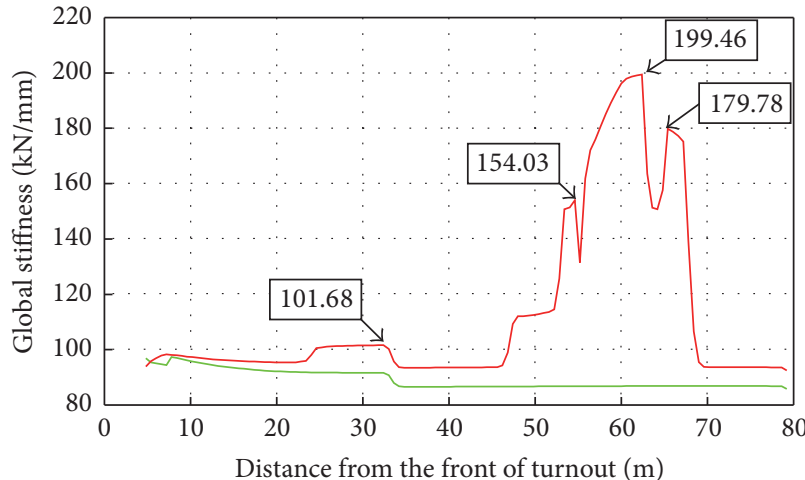

- Stock rail

_ Inner rail

(a)

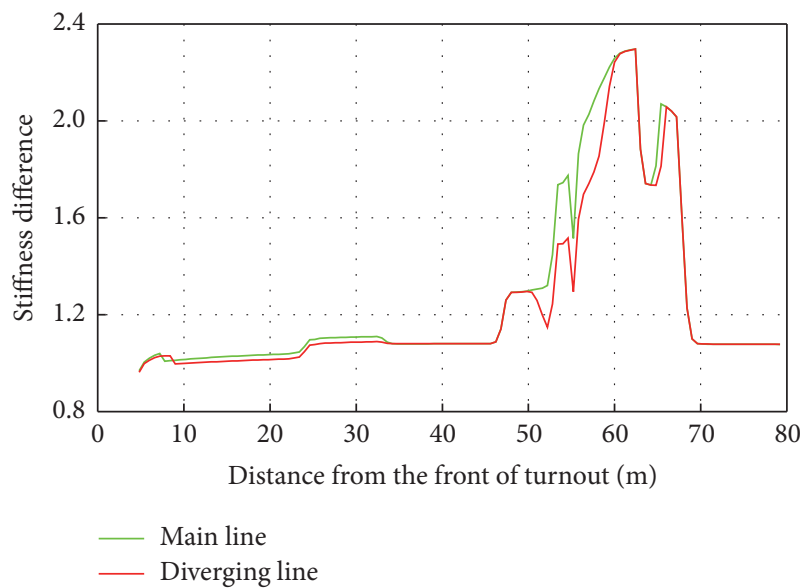

(c)

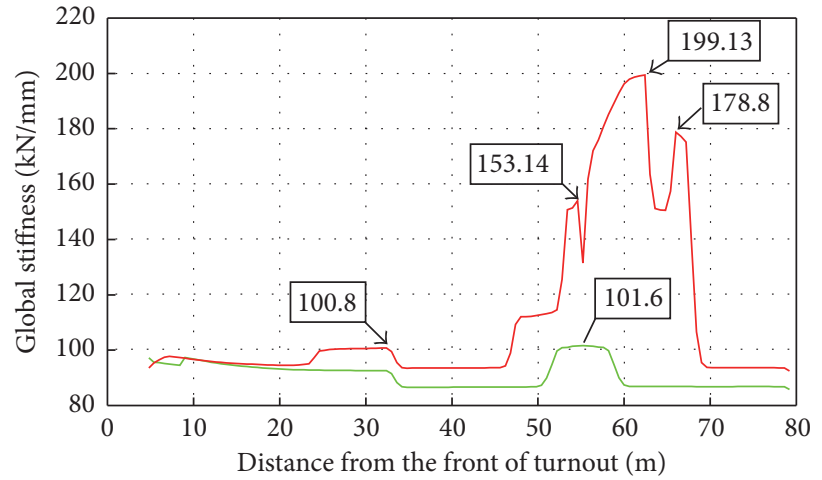

_ Stock rail

_ Inner rail

(b)

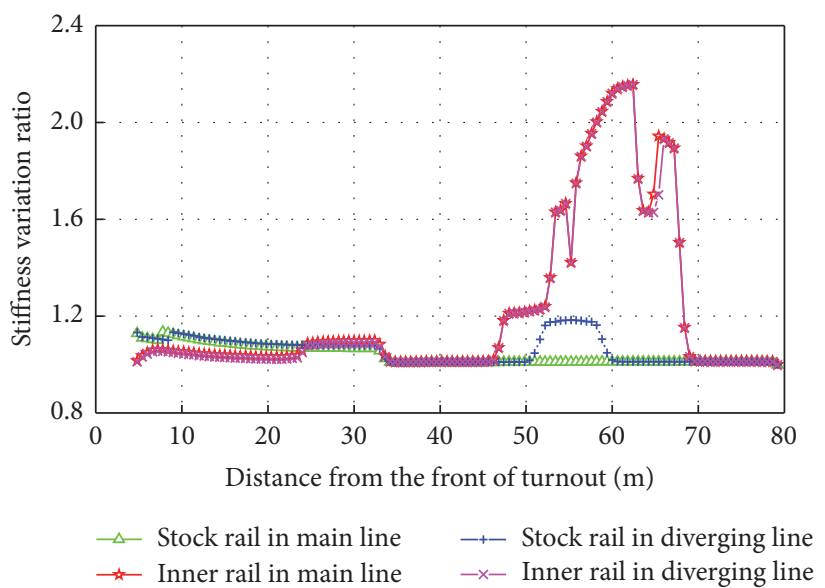

(d)

Figure 4: Distribution of stiffness in a high-speed turnout ((a) the main line; (b) the diverging line; (c) the stiffness difference of turnout rails; (d) the stiffness variation ratio). 
TABLE 2: Redesign of pad stiffness under shared base plates.

\begin{tabular}{|c|c|c|c|c|}
\hline Number & $\begin{array}{c}\text { Original stiffness } \\
((\mathrm{kN} / \mathrm{mm}) / \mathrm{m})\end{array}$ & $\begin{array}{c}\text { Modified stiffness } \\
((\mathrm{kN} / \mathrm{mm}) / \mathrm{m})\end{array}$ & $\begin{array}{c}\text { Number of } \\
\text { turnout sleeper }\end{array}$ & Combination type of rail \\
\hline SP-A & \multirow{8}{*}{100} & 66 & $1 \sim 14$ & Stock rail and switch rail \\
\hline SP-B & & 80 & $15 \sim 19$ & Stock rail and switch rail \\
\hline SP-C & & 92 & $20 \sim 58$ & Stock rail and switch rail \\
\hline CE-A & & 70 & $80 \sim 88$ & Closure rails \\
\hline CE-B & & 40 & $89 \sim 92$ & Closure rails \\
\hline CP-A & & 40 & $93 \sim 104$ & Wing rail and point rail \\
\hline CP-B & & 50 & $105 \sim 114$ & Wing rail and point rail \\
\hline CR-A & & 60 & $85 \sim 98$ & Stock rail and check rail \\
\hline
\end{tabular}

train load, thereby influencing the safety and comfort of highspeed trains when passing the turnout.

\subsection{Optimisation of Stiffness in Railway Turnout. The bend-} ing stiffness of the rails, the size of the spacer blocks, and the supporting stiffness of the rail pads and tie pads can all influence the track stiffness of the turnout zone in a highspeed turnout. The selection of turnout rails does not help much in optimising the turnout stiffness by changing the rail type, due to the limit of service life and manufacturing technology. The size and arrangement of the spacer blocks aim only to ensure the geometric stability of the turnout and the effective transmission of longitudinal forces. Therefore, they are not suitable for optimising the turnout stiffness through redesign. The pads under the turnout rails are thin and cannot be adjusted to any significant degree. They are mainly intended to secure the direct impact between the rail and iron base plate and prevent excessive vertical relative motion between the switch rail and a stock rail. This is in order to avoid influencing the decreased value of the switch rail. The pads under the iron base plates are the main source of elasticity for the fastener system and the stiffness can be adjusted within a wide range. The supporting stiffness can be changed easily through changing the structure of the pads under the iron base plates. For example, the pads under the iron base plates can be grooved or perforated. Therefore, this paper presents a method for optimising the track stiffness distribution of a high-speed turnout by modifying the stiffness of the pads under the iron base plates appropriately. The stiffness optimisation of high-speed railway turnout should satisfy some basic constraints. The global stiffness of a railway turnout should be approximately equal to that of ordinary track; the longitudinal variation of the global stiffness in railway turnout should be within a small range of control; there must be a classification limit of the redesigned pads' stiffness under the shared base plates to guarantee the production and replacement conveniently.

The fastener stiffness of the ballast track region for ordinary track is $50 \mathrm{kN} / \mathrm{mm}$. The pads under the iron base plates are the main source of elasticity. In the turnout zone, the elasticity of the fastener system is derived from the pads under the rails and iron base plates, where the stiffness of the pads under the rails is $200 \mathrm{kN} / \mathrm{mm}$. When the stiffness of the fastener system in the turnout zone is equivalent to that of the ordinary track, the stiffness of the pads under the standard iron base plates (unshared base plates) in the turnout zone will be $66 \mathrm{kN} / \mathrm{mm}$. According to the distribution characteristics of track stiffness for high-speed turnouts calculated in Section 2.2, the redesigned pads and the stiffness are classified into 6 types in this paper, and the presented numerical analysis model is applied to determine the optimal stiffness design by trial and error, as shown in Table 2. The stiffness listed in Table 2 stands for the pads stiffness per unit length. SP stands for the switch panel, CE stands for the closure panel, CP stands for the crossing panel, and CR stands for the section of check rail.

The numerical analysis model for track stiffness in the turnout zone can be used for studying the optimised distribution of the track stiffness in the turnout zone. The distribution of track stiffness in the main and diverging lines of the highspeed turnout is shown (Figure 5).

As shown in Figures 5(a) and 5(b), for the optimised stiffness in a railway turnout, the track stiffness of the straight stock rail is distributed evenly along the longitudinal direction of the line and only fluctuates slightly at the front of the switch; specifically, the maximum stiffness decreases from $97 \mathrm{kN} / \mathrm{mm}$ to $91 \mathrm{kN} / \mathrm{mm}$. The distribution of stiffness of the curved stock rail coincides with that of the straight and only fluctuates by less than $2 \mathrm{kN} / \mathrm{mm}$ at the check rail; specifically, the maximum stiffness decreases from $101 \mathrm{kN} / \mathrm{mm}$ to $93 \mathrm{kN} / \mathrm{mm}$. The distribution of track stiffness along the inner rail in the main line is the same as that in the diverging line, being around $93 \mathrm{kN} / \mathrm{mm}$. Additionally, it only fluctuates at the center of the crossing panel, where the maximum fluctuation amplitude is $18 \mathrm{kN} / \mathrm{mm}$. After the track stiffness is optimised and the maximum stiffness of the main inner rail decreases from $199 \mathrm{kN} / \mathrm{mm}$ to $111 \mathrm{kN} / \mathrm{mm}$, the maximum stiffness of the diverging inner rail decreases from $199 \mathrm{kN} / \mathrm{mm}$ to $111 \mathrm{kN} / \mathrm{mm}$, with both decreasing around $88 \mathrm{kN} / \mathrm{mm}$. As shown in Figures 5(c) and 5(d), after the turnout stiffness is optimised, the stiffness ratio of the inner rail to the stock rail and the change along the longitudinal direction decrease greatly. The maximum stiffness ratio of the inner rail to the stock rail decreases from 2.29 to 1.28 , and the maximum longitudinal variance ratio of the inner rail stiffness decreases from 2.2 to 1.4. 


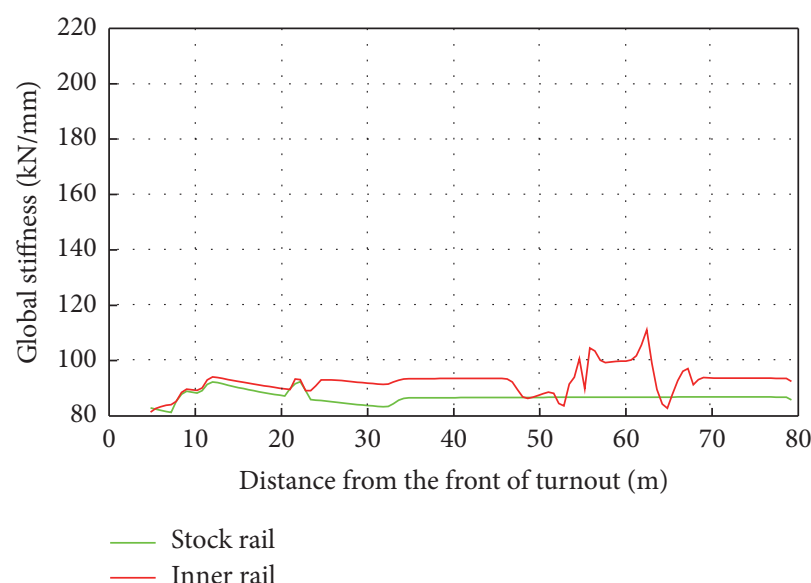

(a)

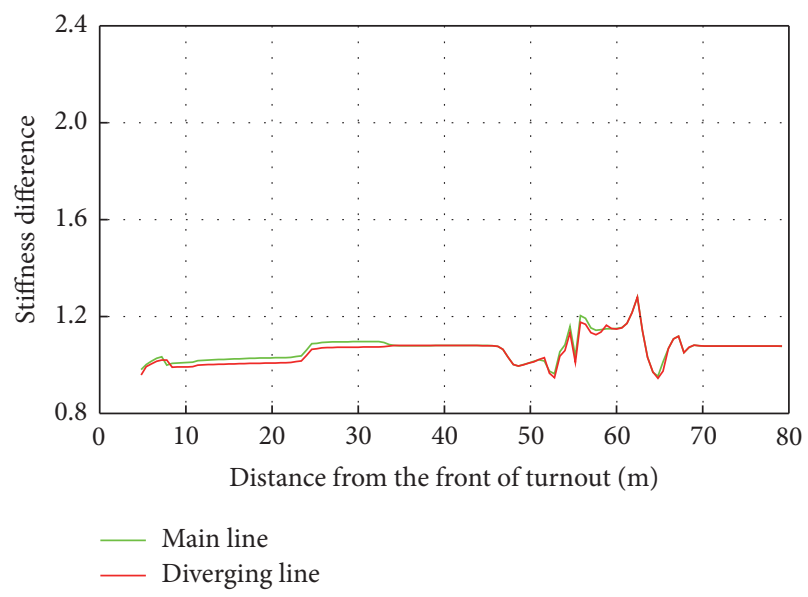

(c)

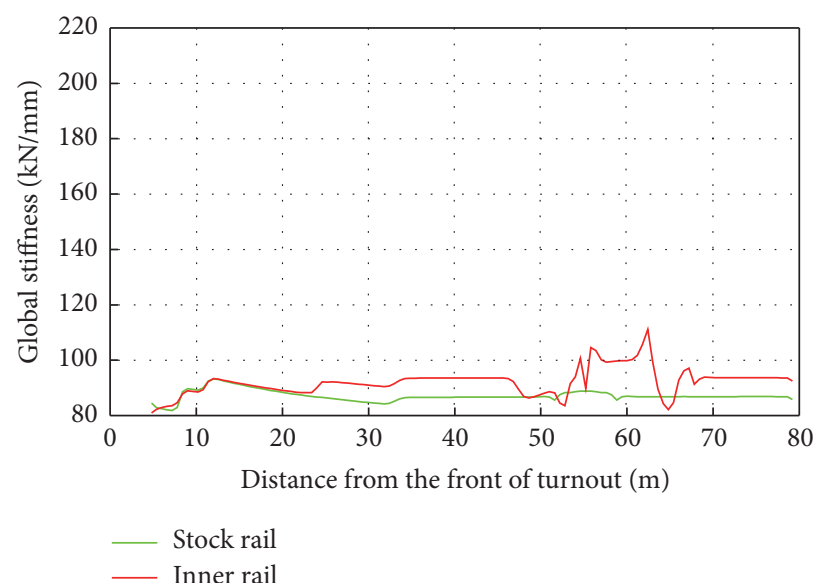

(b)

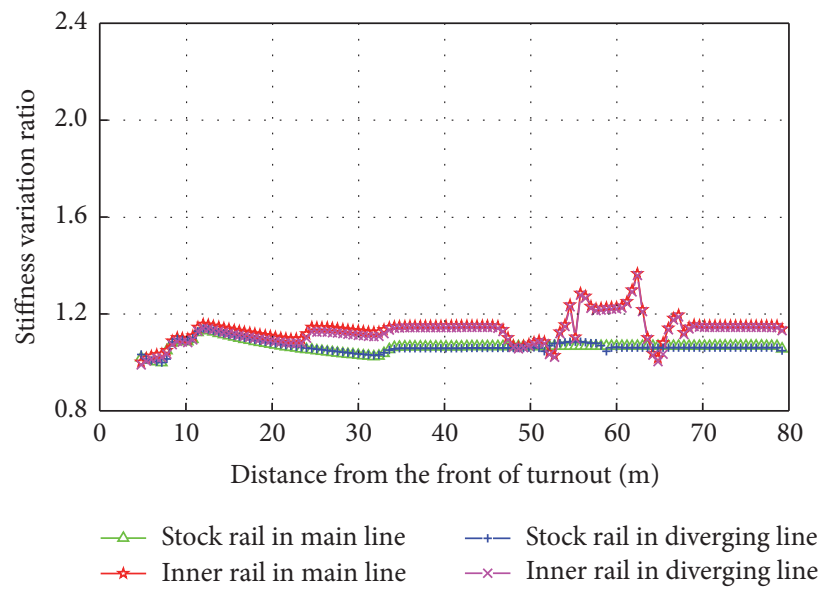

(d)

Figure 5: Distribution of stiffness in high-speed railway turnout after optimisation ((a) the main line; (b) the diverging line; (c) the stiffness difference of turnout rails; (d) the stiffness variation ratio).

\section{Model of Dynamic Train-Turnout Interaction}

3.1. Vehicle Model. The vehicle dynamic model refers to the abstracting of an actual vehicle structure to a reasonable mechanical model, which can be used to research the dynamic response of a vehicle system under the uneven distribution of track stiffness in a high-speed turnout zone. This research applies the Chinese CRH2 high-speed railway vehicle as the prototype and establishes a vehicle dynamic model for four-axle locomotives by neglecting the side bearings, bolsters, and high-speed bogies such as swing bolsters, as shown in Figure 6. During the establishment of the model, the main structural components of the vehicle are assumed to be rigid bodies, including the wheelsets, bogies, and vehicle body. The secondary suspension between the body and the two bogies as well as the primary suspension between the two bogies and four wheelsets are simulated with springs and damping elements. All suspension points have three DOFs along the longitudinal/lateral/vertical directions. The five DOFs, namely, lateral movement, vertical movement, roll, pitch, and yaw, should be considered for all rigid bodies. However as the main motion mode of the wheelsets is rolling, the pitch of the four wheelset rigid bodies can be neglected, so the vehicle dynamic model has 7 rigid bodies and 31 DOFs in total. The parameter values of the Chinese CRH2 high-speed railway vehicle are referred to in [14].

3.2. Model of a High-Speed Railway Turnout. The high-speed railway turnout model is established based on the finite element method. It should be able to reflect the actual structural composition of a turnout, including not only the key components (e.g., the switch panel, closure panel, and crossing panel), but also the coupling components (e.g., the spacer blocks and switching/locking equipment) as well as the subrail foundational elements (e.g., the tie plates, turnout sleepers, and the ballast bed) so as to reflect the parametric vibrations and restrictions on the main structural components (Figure 7).

For the simulation of structural components, all rail parts of the turnout are simulated with point-supported EulerBernoulli beams. All rail nodes have four DOFs, namely, 


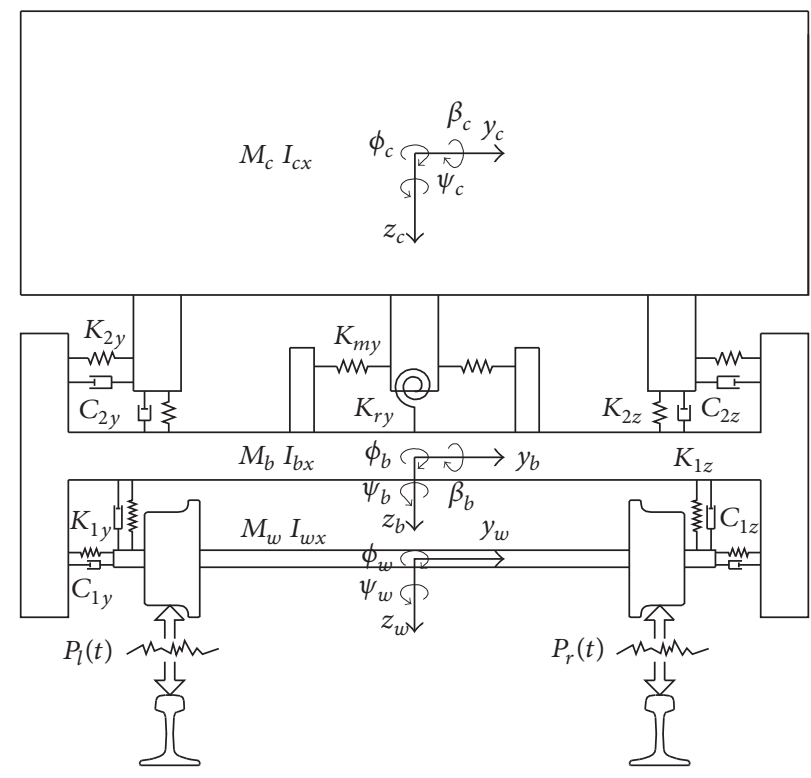

(a)

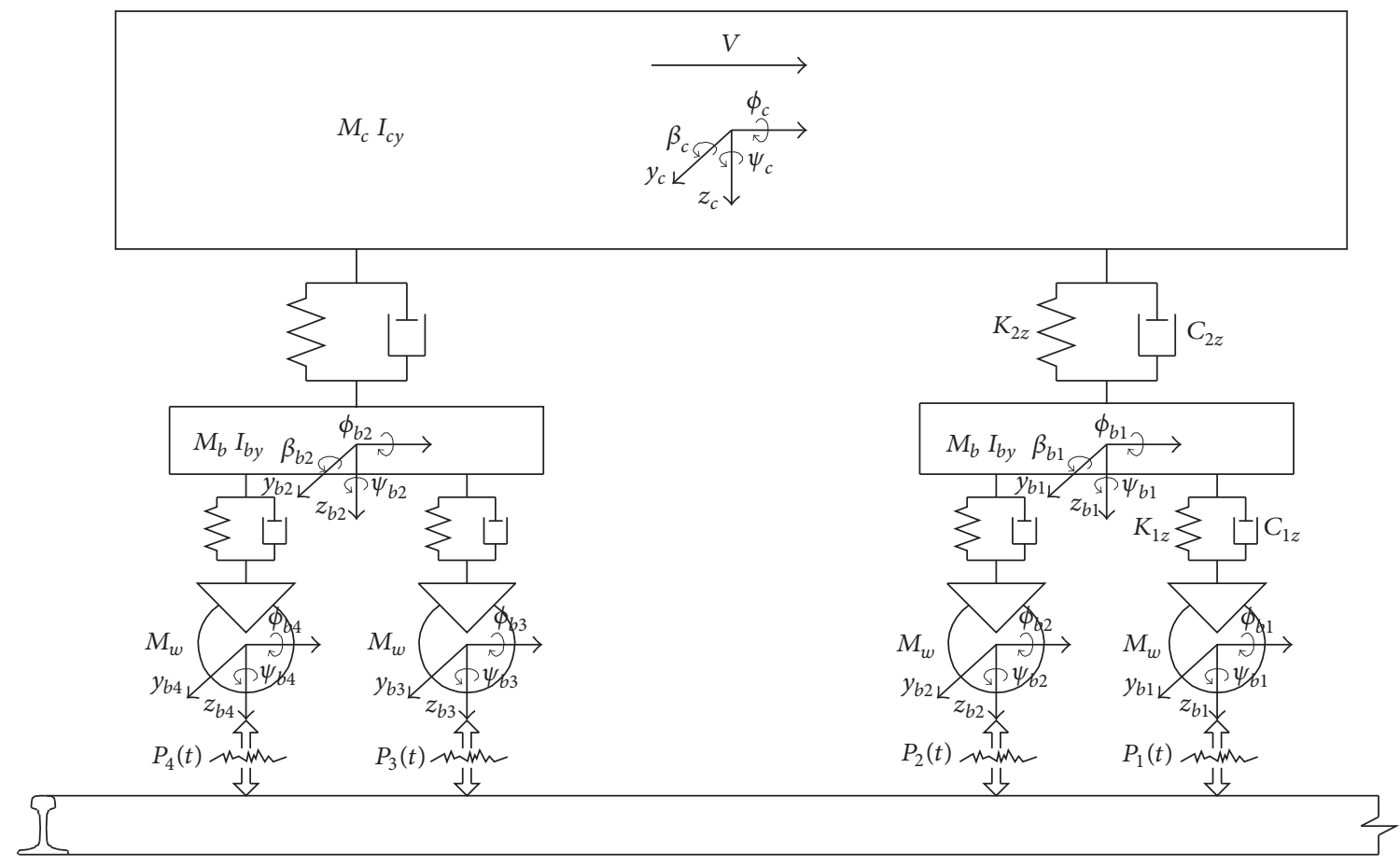

(b)

Figure 6: Dynamic model of a high-speed vehicle. ((a) end view; (b) elevation view).

vertical displacement, lateral displacement, vertical declination, and lateral declination. The turnout sleepers are simulated with vertical bendable constant section Euler-Bernoulli beams and the set nodes are dependent on the support positions of the turnout rails. All turnout sleeper nodes have three DOFs, namely, vertical displacement, lateral displacement, and vertical declination. The force transmission components, fastener system, and ballast bed of the turnout are simulated by using the related spring-damping elements, and these are used to create connection between the rails, rail, and turnout sleeper, as well as the turnout sleeper and ballast bed (Figure 1). The stiffness of the pads under the iron base plates can be identified and adjusted by setting the supporting stiffness of the rail in the dynamic model of high-speed 


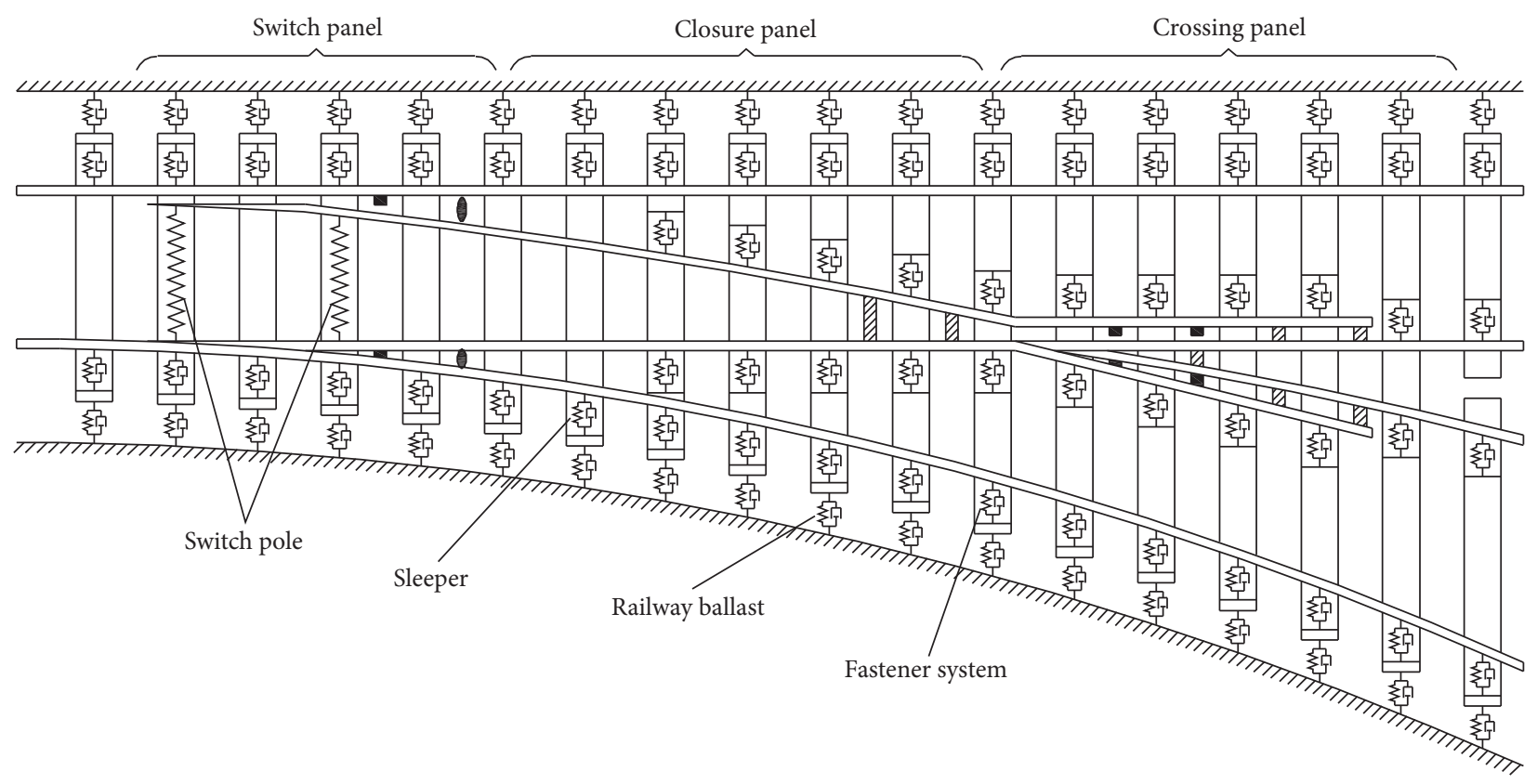

FIGURE 7: Dynamic model of a high-speed railway turnout.

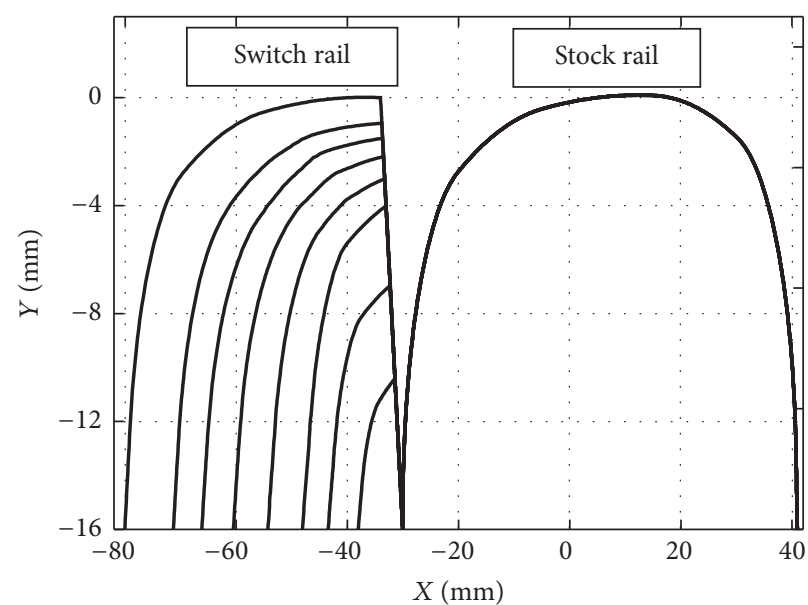

(a)

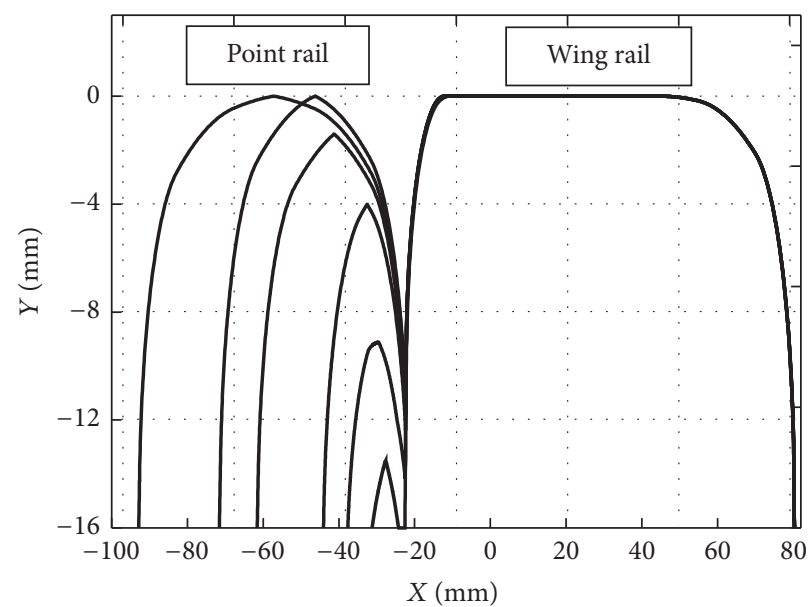

(b)

FIGURE 8: The cross-section sample of a switch rail and point rail ((a) switch panel; (b) crossing panel).

turnout. The varied rail profiles are realized by sampling the cross-sections of switch rails and point rails at certain longitudinal positions (Figure 8).

3.3. Wheel-Rail Contact Model. The wheel-rail contact model serves as a link for the interaction between the dynamic model of the vehicle and the high-speed turnout, which includes the geometric calculations of wheel-rail contact and the solution for the wheel-rail rolling contact force. Based on the previous research $[1,14]$, the space trace line method is adopted to calculate the positions of wheel-rail contact points and contact angles in a high-speed railway turnout. The semi-Hertzian method is used to solve the wheel-rail normal contact problem, including the determination of the number of contact points and normal contact forces. On this basis, the tangential wheel-rail contact force can be calculated with the improved FASTSIM algorithm. The calculated wheelrail contact force can be distributed vertically and laterally in the whole system through the wheel-rail contact angles, reflecting the coupling interaction between the vehicle and turnout systems.

\section{Dynamic Train-Turnout Interaction due to Stiffness Characteristics}

The above model of dynamic train-turnout interaction is applied, taking a train passing the main line of the turnout in the facing direction with a running speed of $250 \mathrm{~km} / \mathrm{h}$ as an 


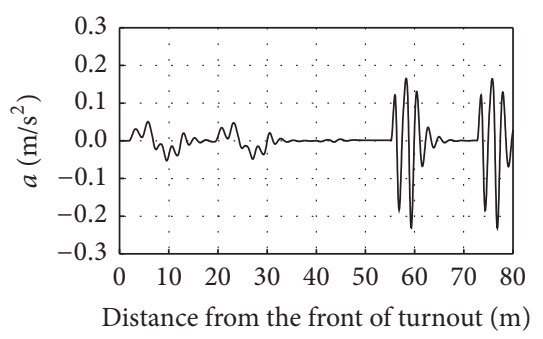

(a)

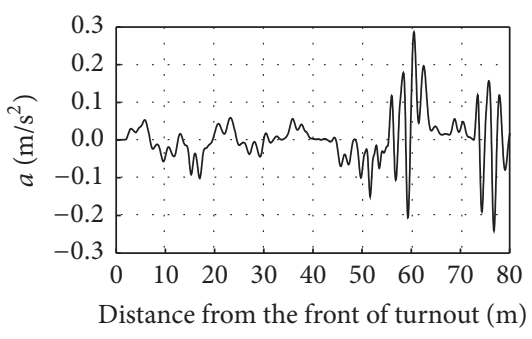

(b)

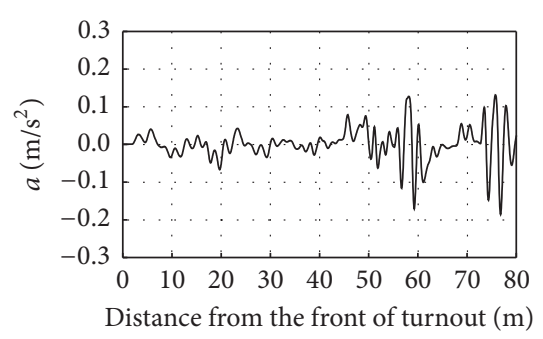

(c)

FIGURE 9: Vertical acceleration of the vehicle body ((a) track stiffness neglected; (b) original track stiffness; (c) optimised track stiffness).

example. The influence of the track stiffness on the dynamic train-turnout interaction is then analysed, including the vertical wheel-rail force, vertical train vibration acceleration, and rail displacement. Moreover, the dynamic response of the train passing the turnout is calculated by the commercial software SIMPACK without considering the variations in track stiffness. In order to make a simplified analysis on the influence of track stiffness on the dynamic train-turnout interaction, the track irregularity is neglected in this research.

4.1. Vertical Acceleration of a Vehicle Body. Figure 9 shows the vertical vibration acceleration of a vehicle body passing through the turnout in the facing direction of the main line. As shown in Figure 9(a), when the variation of the turnout track stiffness is neglected, the vertical acceleration of the vehicle body only noticeably fluctuates when passing the switch and crossing panel, and this is mainly caused by the transfer of wheel load when the train passes by (the switch panel: the wheel load is transferred to the switch rail from the stock rail; crossing panel: the wheel load is transferred to the point rail from the wing rail). The two bogies passing the switch and crossing panel successively cause two similar patterns of fluctuation in the vertical acceleration of the vehicle body. The vertical acceleration of the vehicle body is more intense when passing the crossing panel than when passing the switch and this is caused by the more intense transfer of the wheel load at the crossing panel. The maximum vertical acceleration of a vehicle body passing the switch and crossing panel can reach up to $0.05 \mathrm{~m} / \mathrm{s}^{2}$ and $0.23 \mathrm{~m} / \mathrm{s}^{2}$, respectively. As the rail of the closure panel is the same as that of ordinary track, the vertical acceleration of the vehicle body only fluctuates slightly when passing the closure panel. As shown in Figures 9(b) and 9(c), when considering the characteristics of track stiffness in the turnout, the vertical acceleration of the vehicle body can fluctuate greatly when passing all panels of the turnout. Before stiffness optimisation, the track stiffness values of the turnout differ greatly along the longitudinal and lateral directions. The vibration of vehicle body under the superposition of stiffness variations and wheel load transfer is more intense than when the stiffness variation is neglected, and the vibration of vehicle body caused by each bogie passing the turnout varies. The maximum vertical acceleration of the vehicle body passing the switch, closure, and crossing panels can reach up to $0.1 \mathrm{~m} / \mathrm{s}^{2}, 0.15 \mathrm{~m} / \mathrm{s}^{2}$, and $0.29 \mathrm{~m} / \mathrm{s}^{2}$, respectively.
After stiffness optimisation, the track stiffness values of the turnout do not change much along either the longitudinal or lateral directions. The evenly distributed track stiffness can help to decrease the vibration acceleration of the vehicle body; however, the vertical acceleration of the vehicle body fluctuates when passing each panel of the turnout. The maximum vertical acceleration of the vehicle body passing the switch, closure, and crossing panels can reach up to $0.07 \mathrm{~m} / \mathrm{s}^{2}$, $0.08 \mathrm{~m} / \mathrm{s}^{2}$, and $0.17 \mathrm{~m} / \mathrm{s}^{2}$, respectively. By optimising the track stiffness of the high-speed turnout, the difference between the track stiffness along the longitudinal and lateral directions can decrease greatly, and the vibration of the vehicle body passing the turnout can be reduced and the comfort of the vehicle passing the turnout at a high speed can be improved.

4.2. Vertical Wheel-Rail Contact Force. Figure 10 shows the wheel-rail vertical force at the switch rail side when a vehicle passes through a turnout in the facing direction of the main line. As shown in Figure 10(a), without considering the stiffness variations in the turnout and analogous to the vertical acceleration of the vehicle body, the wheel-rail vertical force only fluctuates significantly when the vehicle passes the switch and crossing panel, which is also caused by the complicated wheel-rail contact relationship. The wheel-rail vertical force at the crossing panel is much higher than that of the switch panel, as the variable cross-section rails are short and the cross-section variation is more obvious, causing a more intense dynamic wheel-rail interaction. The maximum wheel-rail vertical force at the switch panel can reach up to $84 \mathrm{kN}$, and the distance from the front of the turnout is $6.77 \mathrm{~m}$. Meanwhile, the maximum wheel-rail vertical force at the crossing panel can reach up to $132 \mathrm{kN}$, at a distance from the front of the turnout of $56 \mathrm{~m}$. Moreover, the position with the maximum wheel-rail vertical force at the switch/crossing panels is within the range of the wheels load transfer, while the wheel-rail vertical force at the closure panel is almost the same as the dead weight of the wheels. As shown in Figures $10(\mathrm{~b})$ and $10(\mathrm{c})$, considering the characteristics of the track stiffness in turnout, the wheel-rail vertical force fluctuates greatly when the vehicle passes all panels of the turnout, and the position with peak wheel-rail vertical force changes. Before stiffness optimisation, the uneven distribution of the track stiffness in turnout intensifies the dynamic wheel-rail interaction. The maximum wheel-rail vertical forces in the switch, closure, and crossing panels are $93 \mathrm{kN}, 91 \mathrm{kN}$, and 


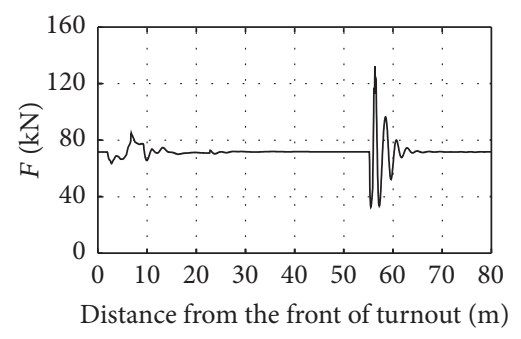

(a)

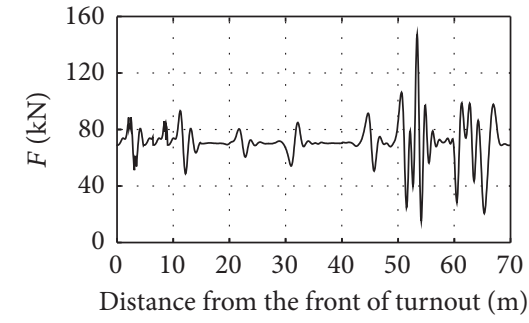

(b)

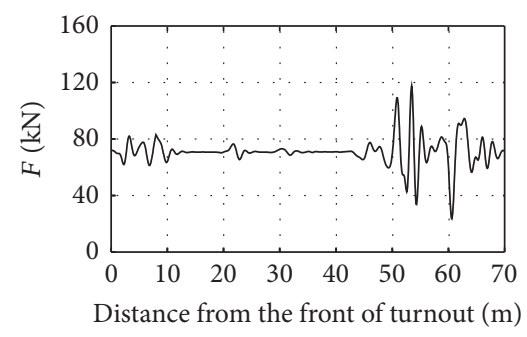

(c)

FIGURE 10: Wheel-rail vertical forces ((a) track stiffness neglected; (b) original track stiffness; (c) optimised track stiffness).

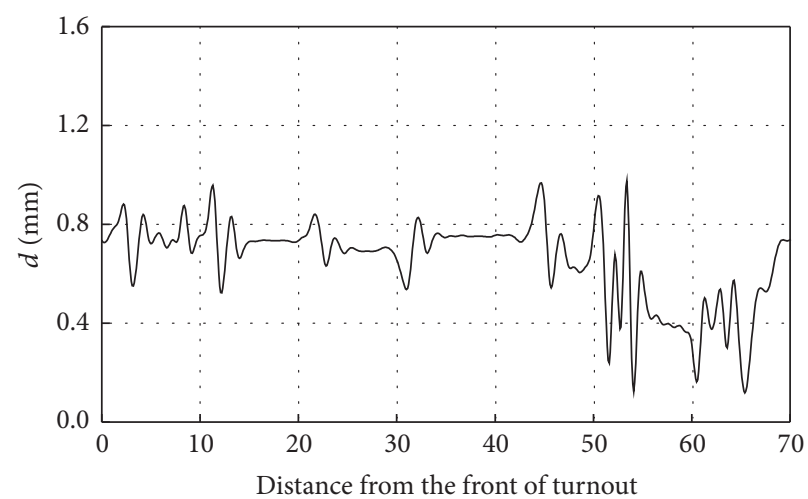

(a)

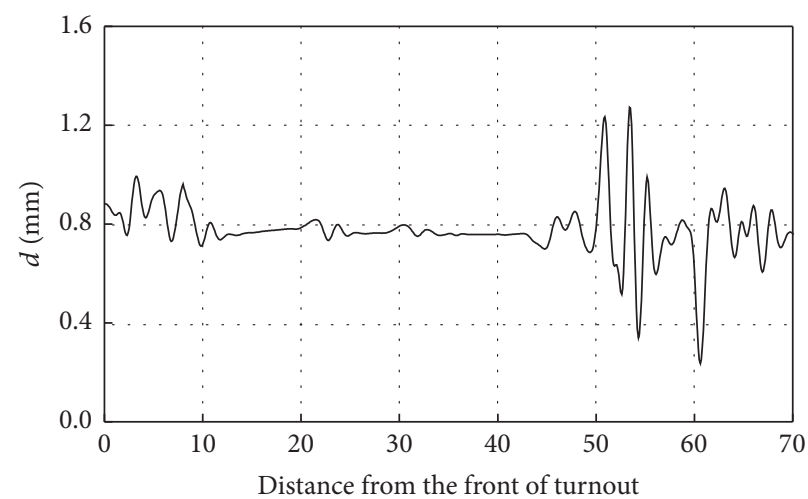

(b)

FIGURE 11: Vertical rail displacement ((a) original track stiffness; (b) optimised track stiffness).

$147 \mathrm{kN}$, respectively. Additionally, the minimum wheel-rail vertical force at the crossing panel is $15 \mathrm{kN}$ and the wheel unloading rate is 0.79 , which are close to the limit value for safe operation. After stiffness optimisation, the track stiffness in the turnout does not change much along the longitudinal and lateral directions. The evenly distributed track stiffness can significantly help to improve the wheel-rail interaction at the turnout zone; the wheel-rail vertical force fluctuates when passing each panel of the turnout. The maximum wheel-rail vertical force passing the switch, closure, and crossing panels can reach up to $82 \mathrm{kN}, 77 \mathrm{kN}$, and $117 \mathrm{kN}$, respectively. By optimising the track stiffness in the high-speed turnout, the uneven distribution of the turnout track stiffness can decrease greatly, and the dynamic wheel-turnout rail interaction and the safety of the vehicle passing the turnout at a high speed can be improved.

4.3. Rail Displacement. Figure 11 shows the vertical rail displacement at the switch rail side when a vehicle passes through a turnout in the facing direction of the main line. As rails are assumed to be mass-free rigid bodies, rail displacement cannot be calculated by using SIMPACK software. Therefore, the distribution of vertical rail displacement is analysed when only the characteristics of the track stiffness are considered. As shown in Figures 11(a) and 11(b), the vertical rail displacement fluctuates greatly at the switch and crossing panels. After stiffness optimisation, the integral track stiffness decreases to a certain extent, and therefore the rail displacement is higher than before the rail stiffness is optimised. Before stiffness optimisation, the maximum values of rail displacement at the switch/crossing panels are $0.96 \mathrm{~mm}$ and $0.98 \mathrm{~mm}$, respectively. After the turnout track stiffness is optimised, the maximum values of rail displacement at the switch and crossing panels are $0.99 \mathrm{~mm}$ and $1.27 \mathrm{~mm}$, respectively; and the uneven distribution of the track stiffness in the high-speed turnout can be greatly decreased; however the dynamic displacement or vibration of the rail will increase, so when the track stiffness in the turnout is optimised the enhancement of the dynamic displacement and vibration of the turnout caused by the variations in track stiffness should be carefully considered.

\section{Conclusions}

In this paper, a numerical model is established for analysing the distribution characteristics of track stiffness in a highspeed railway turnout. In this model, the influence of various force transmission components (such as different types of rails, shared iron base plates sleepers of different lengths, and spacer blocks) is considered. Therefore, the distribution characteristics of track stiffness in a high-speed railway turnout can be reflected more realistically. By taking a highspeed turnout of ballast track in China as an example and using the numerical model established in this paper as a basis, the distribution characteristics of track stiffness in the main and diverging lines of the high-speed turnout are analysed. In 
addition, the method for optimising the stiffness of the pads under shared iron base plates is presented and the influence of the variations in track stiffness on the dynamic vehicleturnout interaction is studied. The following conclusions are reached:

(1) The uneven distribution of track stiffness in the highspeed ballast turnout along the longitudinal direction is especially dependent on turnout structure. A highspeed turnout has different types of rails such as switch rails, stock rails, wing rails, point rails, and check rails. More than one rail is placed on a single iron base plate. Meanwhile, different length sleepers and spacer blocks are used for connecting different rails. All of these factors can influence the distribution characteristics of track stiffness in high-speed railway turnouts.

(2) The distribution characteristics of track stiffness in a Chinese number 18 high-speed turnout are obtained according to the numerical model established in this paper for analysing the track stiffness. The track stiffness in high-speed turnouts varies greatly along the longitudinal and lateral directions of the railway line. The maximum variance ratio of the inner rail along the longitudinal direction can reach up to $216 \%$. As rails are connected by the spacer blockers and more than one rail shares the iron base plate at the crossing panel, the track stiffness of the inner rail at this section is at most 2.29 times higher than that of the stock rail. The distribution characteristics of track stiffness in the main and diverging lines are almost the same except for the obvious difference at the check rail in the diverging line.

(3) The track stiffness in the high-speed turnout can be optimised by modifying the stiffness of the pads under the shared iron base plate. The distribution characteristics of track stiffness after stiffness optimisation are analysed by using the presented numerical analysis model and dynamic vehicle-turnout coupling model. The difference between the track stiffness along the longitudinal and lateral directions can decrease greatly, and the dynamic train-turnout interaction and the comfort of the vehicle passing the turnout at a high speed can be improved, while the dynamic displacement of the turnout rails can be enhanced.

(4) The numerical analysis model for track stiffness presented can be used for the study and optimisation of vertical track stiffness in the high-speed railway turnouts. In this paper, the presented numerical analysis model is applied to determine the optimal stiffness design by trial and error. However, the proposed pads stiffness under shared base plates in the paper may not be the most optimal; it needs to be investigated and studied based on mathematical optimisation methods in the further research. Furthermore, the stiffness optimisation for the lateral direction of railway turnouts will be also preceded to further improve the dynamic train-turnout interaction.

\section{Competing Interests}

The authors declare that there are no competing interests regarding the publication of this paper.

\section{Acknowledgments}

The present work has been supported by the National Natural Science Foundation of China (51425804, U1334203, 51608459, U1234201, and 51378439) and the Project funded by China Postdoctoral Science Foundation (2016M590898).

\section{References}

[1] J. Xu, P. Wang, X. Ma, J. Xiao, and R. Chen, "Comparison of calculation methods for wheel-switch rail normal and tangential contact," Proceedings of the Institution of Mechanical Engineers, Part F: Journal of Rail and Rapid Transit, 2016.

[2] G. Kouroussis, D. P. Connolly, K. Vogiatzis, and O. Verlinden, "Modelling the environmental effects of railway vibrations from different types of rolling stock: a numerical study," Shock and Vibration, vol. 2015, Article ID 142807, 15 pages, 2015.

[3] J. N. Varandas, P. Hölscher, and M. A. G. Silva, "Dynamic behaviour of railway tracks on transitions zones," Computers and Structures, vol. 89, no. 13-14, pp. 1468-1479, 2011.

[4] P. Woodward, J. Kennedy, O. Laghrouche, D. Connolly, and G. Medero, "Study of railway track stiffness modification by polyurethane reinforcement of the ballast," Transportation Geotechnics, vol. 1, no. 4, pp. 214-224, 2014.

[5] J. C. O. Nielsen, G. Lombaert, and S. François, "A hybrid model for prediction of ground-borne vibration due to discrete wheel/rail irregularities," Journal of Sound and Vibration, vol. 345, pp. 103-120, 2015.

[6] G. Kouroussis, D. P. Connolly, G. Alexandrou, and K. Vogiatzis, "The effect of railway local irregularities on ground vibration," Transportation Research Part D: Transport \& Environment, vol. 39, pp. 17-30, 2015.

[7] G. Kouroussis, D. P. Connolly, G. Alexandrou, and K. Vogiatzis, "Railway ground vibrations induced by wheel and rail singular defects," Vehicle System Dynamics, vol. 53, no. 10, pp. 1500-1519, 2015.

[8] R. F. Lagos, A. Alonso, J. Vinolas, and X. Pérez, "Rail vehicle passing through a turnout: analysis of different turnout designs and wheel profiles," Proceedings of the Institution of Mechanical Engineers, Part F: Journal of Rail and Rapid Transit, vol. 226, no. 6, pp. 587-602, 2012.

[9] Y. Q. Sun, C. Cole, and M. McClanachan, "The calculation of wheel impact force due to the interaction between vehicle and a turnout," Proceedings of the Institution of Mechanical Engineers Part F: Journal of Rail and Rapid Transit, vol. 224, no. 5, pp. 391403, 2010.

[10] M. Sebes, J. B. Ayasse, H. Chollet, P. Pouligny, and B. Pirat, "Application of a semi-Hertzian method to the simulation of vehicles in high-speed switches," Vehicle System Dynamics, vol. 44, supplement 1, pp. 341-348, 2006. 
[11] E. Kassa, C. Andersson, and J. C. O. Nielsen, "Simulation of dynamic interaction between train and railway turnout," Vehicle System Dynamics, vol. 44, no. 3, pp. 247-258, 2006.

[12] E. Kassa and G. Johansson, "Simulation of train-turnout interaction and plastic deformation of rail profiles," Vehicle System Dynamics, vol. 44, S1, pp. 349-359, 2006.

[13] S. Bruni, I. Anastasopoulos, S. Alfi, A. Van Leuven, and G. Gazetas, "Effects of train impacts on urban turnouts: modelling and validation through measurements," Journal of Sound and Vibration, vol. 324, no. 3-5, pp. 666-689, 2009.

[14] S. Alfi and S. Bruni, "Mathematical modelling of train-turnout interaction," Vehicle System Dynamics, vol. 47, no. 5, pp. 551-574, 2009.

[15] J. Y. Zhu and D. J. Thompson, "Characterization of forces, dynamic response, and sound radiation from an articulated switch sleeper in a turnout system," Proceedings of the Institution of Mechanical Engineers Part F: Journal of Rail and Rapid Transit, vol. 224, no. 2, pp. 53-60, 2010.

[16] B. A. Pålsson and J. C. O. Nielsen, "Track gauge optimisation of railway switches using a genetic algorithm," Vehicle System Dynamics, vol. 50, supplement 1, pp. 365-387, 2012.

[17] X. Li, J. C. O. Nielsen, and B. A. Pålsson, "Simulation of track settlement in railway turnouts," Vehicle System Dynamics, vol. 52, no. 1, pp. 421-439, 2014.

[18] C. Wan, V. L. Markine, and I. Y. Shevtsov, "Analysis of train/ turnout vertical interaction using a fast numerical model and validation of that model," Proceedings of the Institution of Mechanical Engineers, Part F: Journal of Rail and Rapid Transit, vol. 228, no. 7, pp. 730-743, 2014.

[19] J. Xu, P. Wang, L. Wang, and R. Chen, "Effects of profile wear on wheel-rail contact conditions and dynamic interaction of vehicle and turnout," Advances in Mechanical Engineering, vol. 8, no. 1, pp. 1-14, 2016.

[20] P. Wang, J. Xu, K. Xie, and R. Chen, "Simulation of rail profile evolution in the railway turnout due to non-uniform wear," in Proceedings of the 10th International Conference on Contact Mechanics and Wear of Wheel/Rail Systems, Colorado Springs, Colo, USA, August 2015.

[21] J. Zhu, "On the effect of varying stiffness under the switch rail on the wheel-rail dynamic characteristics of a high-speed turnout," Proceedings of the Institution of Mechanical Engineers Part F: Journal of Rail and Rapid Transit, vol. 220, no. 1, pp. 69-75, 2006.

[22] V. L. Markine, M. J. M. M. Steenbergen, and I. Y. Shevtsov, "Combatting RCF on switch points by tuning elastic track properties," Wear, vol. 271, no. 1-2, pp. 158-167, 2011.

[23] B. A. Pålsson and J. C. O. Nielsen, "Dynamic vehicle-track interaction in switches and crossings and the influence of rail pad stiffness-field measurements and validation of a simulation model," Vehicle System Dynamics, vol. 53, no. 6, pp. 734-755, 2015.

[24] M. Oregui, Z. Li, and R. Dollevoet, "An investigation into the modeling of railway fastening," International Journal of Mechanical Sciences, vol. 92, pp. 1-11, 2015.

[25] P. Wang, L. Wang, R. Chen, J. Xu, J. Xu, and M. Gao, "Overview and outlook on railway track stiffness measurement," Journal of Modern Transportation, vol. 24, no. 2, pp. 89-102, 2016. 


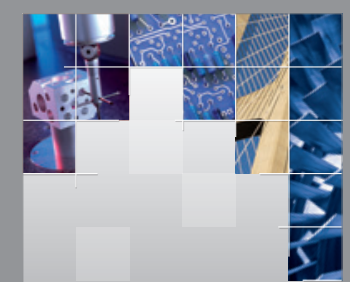

\section{Enfincering}
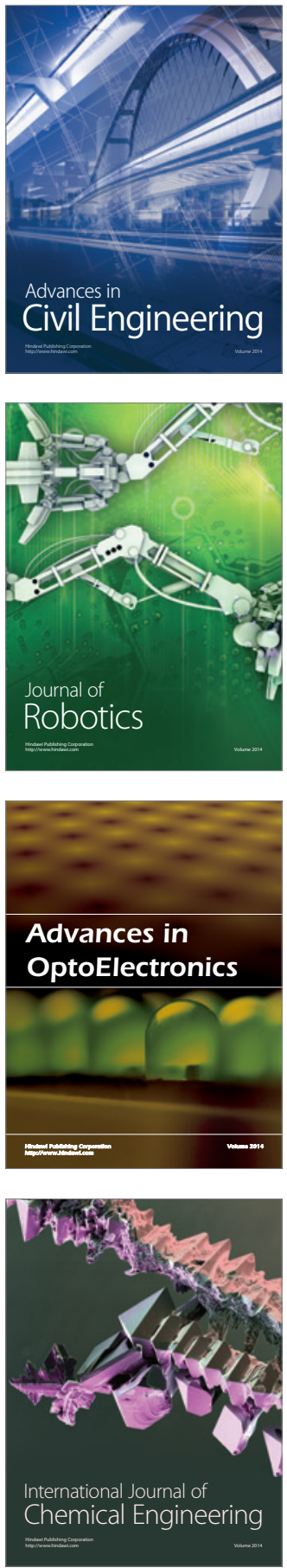

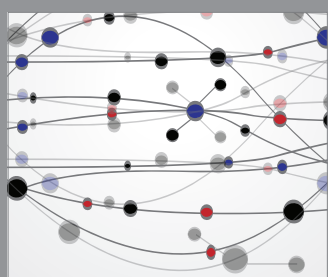

The Scientific World Journal

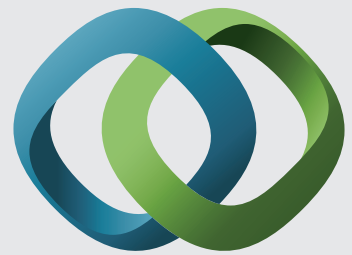

\section{Hindawi}

Submit your manuscripts at

http://www.hindawi.com
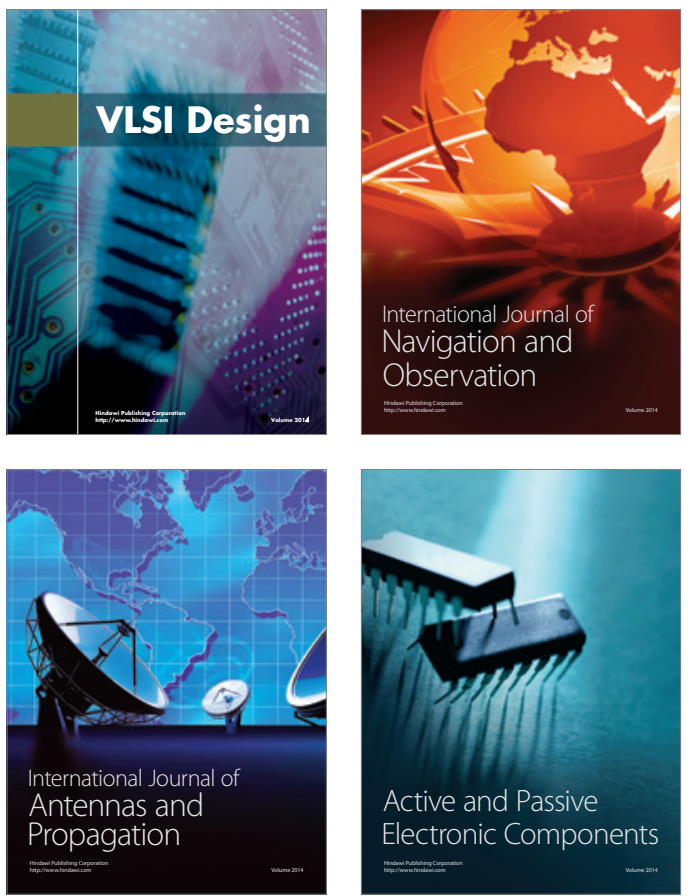
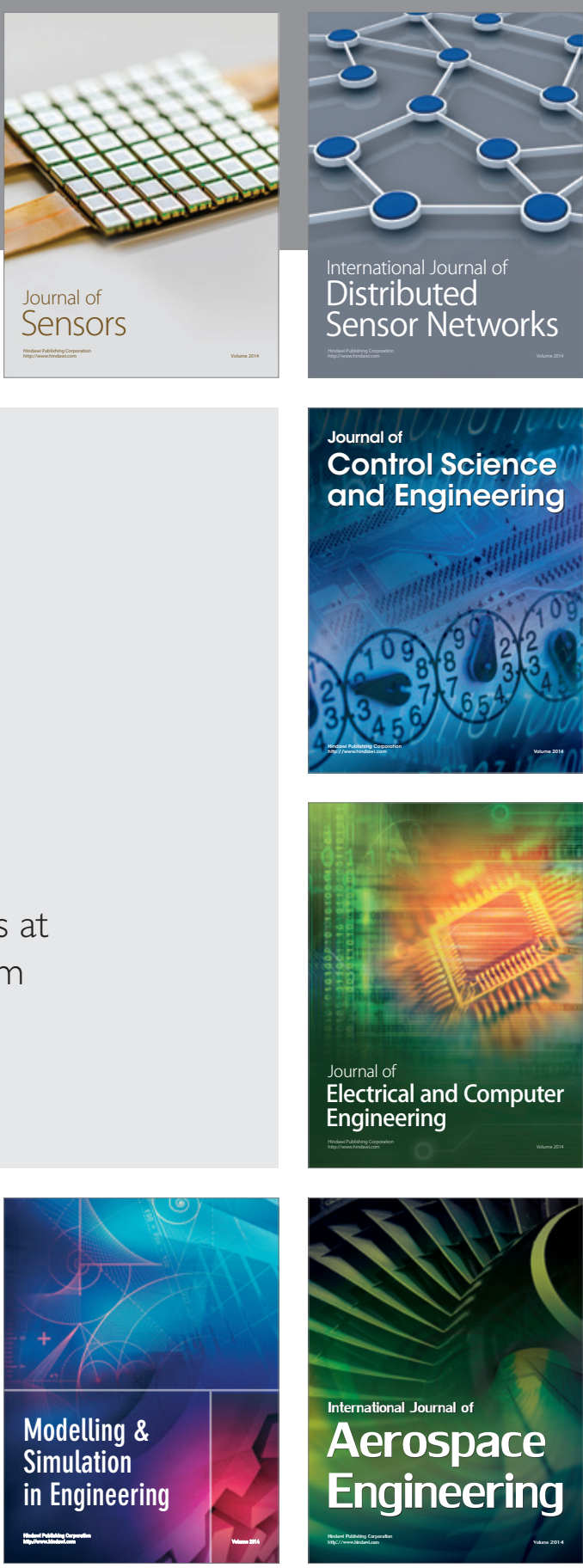

International Journal of

Distributed

Sensor Networks

Journal of

Control Science

and Engineering
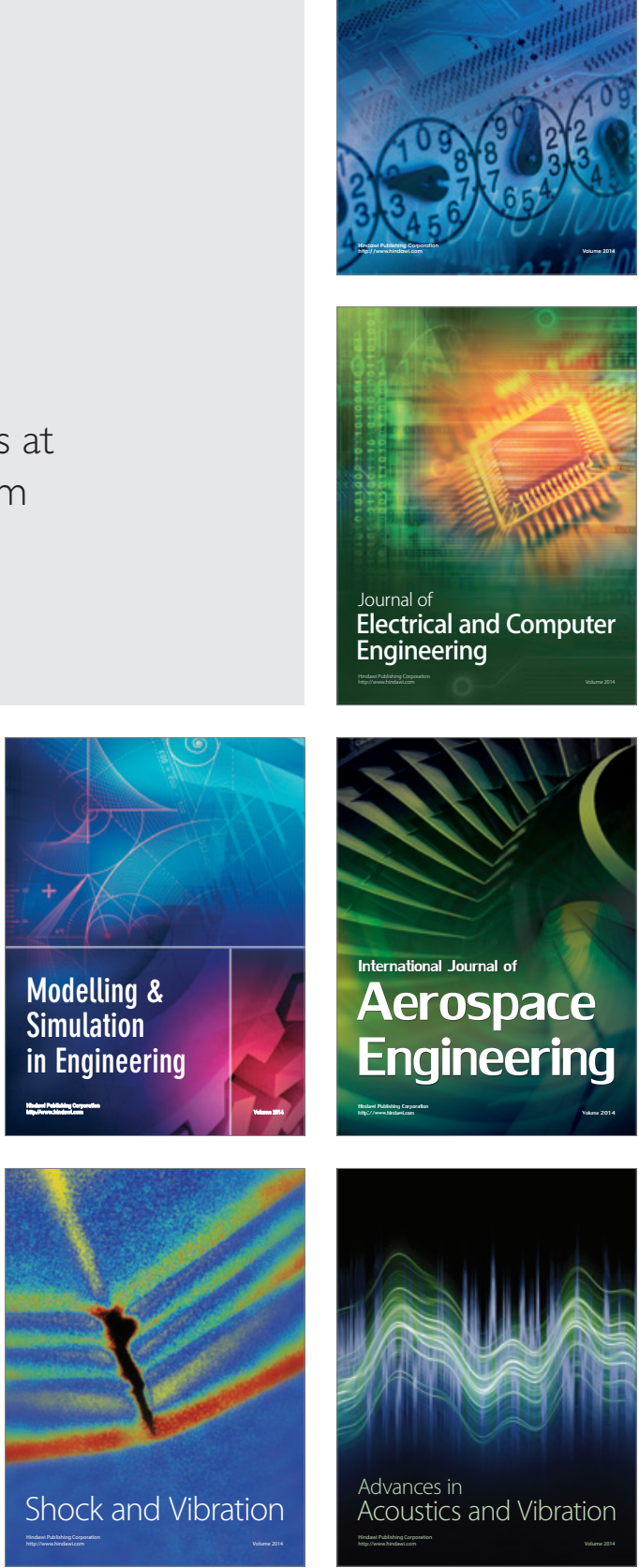